Omni-Akuatika, 14 (1): 36-43, 2018
ISSN: 1858-3873 print / 2476-9347 online
Research Article
journal homepage: http://ojs.omniakuatika.net

\title{
Seahorse Acoustic Reflection on Active and Passive Moving Condition: A preliminary Observation in Watertank
}

\author{
Dony Apdillah ${ }^{12^{\star}}$, Indra Jaya ${ }^{3}$, Henry Munandar Manik ${ }^{3}$, Totok Hestirianoto ${ }^{3}$, Try Febrianto ${ }^{4}$ \\ ${ }^{1}$ Post Graduate School of Marine Technology, Bogor Agricultural University, Bogor, Indonesia \\ ${ }^{2}$ Department of Marine Science, Faculty of Marine Science and Fisheries - Raja Ali Haji Maritime University, \\ Tanjungpinang, Indonesia \\ ${ }^{3}$ Department of Marine Science and Technology, Bogor Agricultural University, Bogor, Indonesia \\ ${ }^{4}$ Marine and Coastal Resource Research Center, Raja Ali Haji Maritime University, Tanjungpinang, Indonesia
}

"Corresponding author : donyapdillah@umrah.ac.id

Received 2 November 2017; Accepted 14 January 2018; Available online 21 May 2018

\begin{abstract}
Identification and estimation of seahorse (Hippocampus sp.) population in the marine environment are difficult to obtain. Nowadays, the observations use visual techniques, biology and statistics. Bio-statistics approach has some limitations. An approach was required to provide more accurate information, comprehensive, and based on telemetry (underwater acoustic). Acoustic reflection is important information to observe underwater objects that can be used for stock assessment and behavioral studies. This research is a preliminary observation and measurement of seahorse Target Strength (TS). The results show that there are differences in TS value of seahorse at the active and passive moving condition. The fluctuations of TS values in active conditions are higher than those in passive conditions. This study has also found that the average TS value of seahorse in active moving conditions is $-54.49 \mathrm{~dB}( \pm 3 \mathrm{~dB})$. It is greater than the mean TS value in passive moving conditions $-59.64 \mathrm{~dB}( \pm 3 \mathrm{~dB})$. The approach of immobile fish (the passive moving condition) is better to increase the correlation value between TS to size. The relationship between TS and the size of the seahorse are discussed in the results of this study.
\end{abstract}

Keywords : Seahorse, acoustic reflection, echosounder, target strength

\section{Introduction}

In 2002, seahorses have been regulated in the Convention of International Trade in Endangered Species of Wild Fauna and Flora (CITES) appendix II. Seahorses are listed on the Red List of Threatened Species (2014) due to the decreasing of their population in nature (Project Seahorse, 2009).

The identification and estimation of the seahorse present in the coastal marine are difficult to obtain. Nowadays, to find and monitor the seahorse's population in seawaters around the world still use conventional method (visual, biological and statistical techniques) (Foster and Vincent, 2004; Curtis 2007; Correia et al. 2014; Yip et al., 2014). The bio-statistic approach has some limitations, such as time consuming and low accuracy. It needs an approach that can provide more accurate, comprehensive, and based on telemetry (Underwater Acoustic).

Implementation of active acoustic technology through basic research to calculate the acoustic reflection properties known as Target Strength (TS) of a seahorse was necessary. TS is the strength of the sound reflection (echo) of the fish as a single target (Ehrenberg, 1984). Acoustic reflection information from TS is important information of underwater acoustic technology that can be used for stock assessment (Manik, 2009). The difficulty of hydro acoustic survey techniques in quantifying the abundance of fish is almost dependent on the knowledge of the distribution of TS values that will be the object of observation (Dawson and Karp, 1990).

This research is preliminary observation and measurement TS value of the seahorse's. This is the first research conducted observations of acoustic reflections of the seahorse. This initial research will be focused on measurement of seahorse's TS on active and passive moving conditions. The results of this study are expected to be useful for describing the acoustic energy generated by one of the physiology factors (Ona, 1990; horne, 2003). The physiology factor can influence the prediction of TS value and increase the accuracy of seahorse's backscattering strength to stock assessment in coastal waters. 


\section{Material and Methods}

This research was conducted in Laboratory of Aquaculture Faculty of Marine Science and Fisheries UMRAH Tanjungpinang. Field data collection is conducted during January-March 2017. Data analysis is conducted at Marine Acoustics and Instrumentation Laboratory, Department of Marine Science and Technology, Bogor Agricultural University in May 2017.

\section{Seahorse collection and experimental setup}

The data is collected using an experiment watertank made of cement with a diameter of 2.7 $\mathrm{m} \times$ height $1.7 \mathrm{~m}$. Water filled into the watertank that filtered out from the ocean waters is sucked using a pump machine. The water height is 1.6 $\mathrm{m}$. Observed seahorse (Hippocampus sp.) is originally from the Bintan Island coastal waters. Seahorses are living moved into the watertank and placed on an artificial substrate made of nylon rope at a distance of $1.1 \mathrm{~m}$ from a transducer, this is adjusted by the near field and far field distance (Medwind and Clay, 1997). Further, the aquatic environmental parameters (salinity and temperature) are measured and used for sound speed (c) computation. Seahorse data recording is done using scientific echosounder, single beam SIMRAD EK-15 frequency $200 \mathrm{Khz}$. The transducer is placed as a downward looking (vertical) position. The setting and specification of echosounder is listed in Table 1.

Instrument calibration is done by on-axis acoustic transmission technique using sphere ball, based on standard procedure (Simrad, 2012). Baseline condition is firstly compiled, the water tank's backscattering recording is conducted without the presence of the seahorse. An underwater camera, is placed on the wall side of the watertank during the data transmitting, is capturing seahorse. The setup of the experiment is shown in Figure 1. Image captured and recording of seahorse's acoustic data are done at the same time in order to monitoring the behavior orientation of the seahorse.

\section{Data analysis}

The data analysis and calculation of the seahorse target strength value (TS) is done using Sonar-4 software (Balk and Lindem, 2015). Calculation of TS value used equation (Burczynski and Johnson, 1986; MacLennan et. al., 2002) :

$$
\mathrm{TS}=10 \log \left(\sigma_{\mathrm{bs}} / 4 \pi\right)
$$

Where $\sigma_{b s}$ backscattering cross section, on the measurement of the acoustic signal from a single target using the sonar equation (Simmonds and MacLennan et.al., 2005) :

$$
\begin{gathered}
E L=S L-2 T L+T S \\
E L=S L-40 \log 10(R)-2 \alpha R+T S+2 B(\theta)
\end{gathered}
$$

Where EL is the echo level, SL is the source level, $R$ is the range (the propagation distance), $\alpha$ is the absorption coefficient, $B(\theta)$ is a transducer beam pattern as a function of the beam $(\theta)$. The collected acoustic data is statistically analyzed by linear regression and anova ( $p$ value $<0,001$ ) using $R$ software (R Core Team, 2016).

Table 1. Settings and specification of the echosounder during target strength (TS) measurement

\begin{tabular}{ll}
\hline Type of transducer & SIMRAD ES200-7C \\
Transducer shape & Circular \\
Transmission frequency $(\mathrm{kHz})$ & 200 \\
Transmitting power $(\mathrm{W})$ & 45 \\
Beam width & $26^{\circ}$ \\
Pulse length (ms) & 0.128 \\
Ping rate (ping s ${ }^{1}$ ) & 10 \\
Minimum threshold $(\mathrm{dB})$ & -70 \\
\hline
\end{tabular}




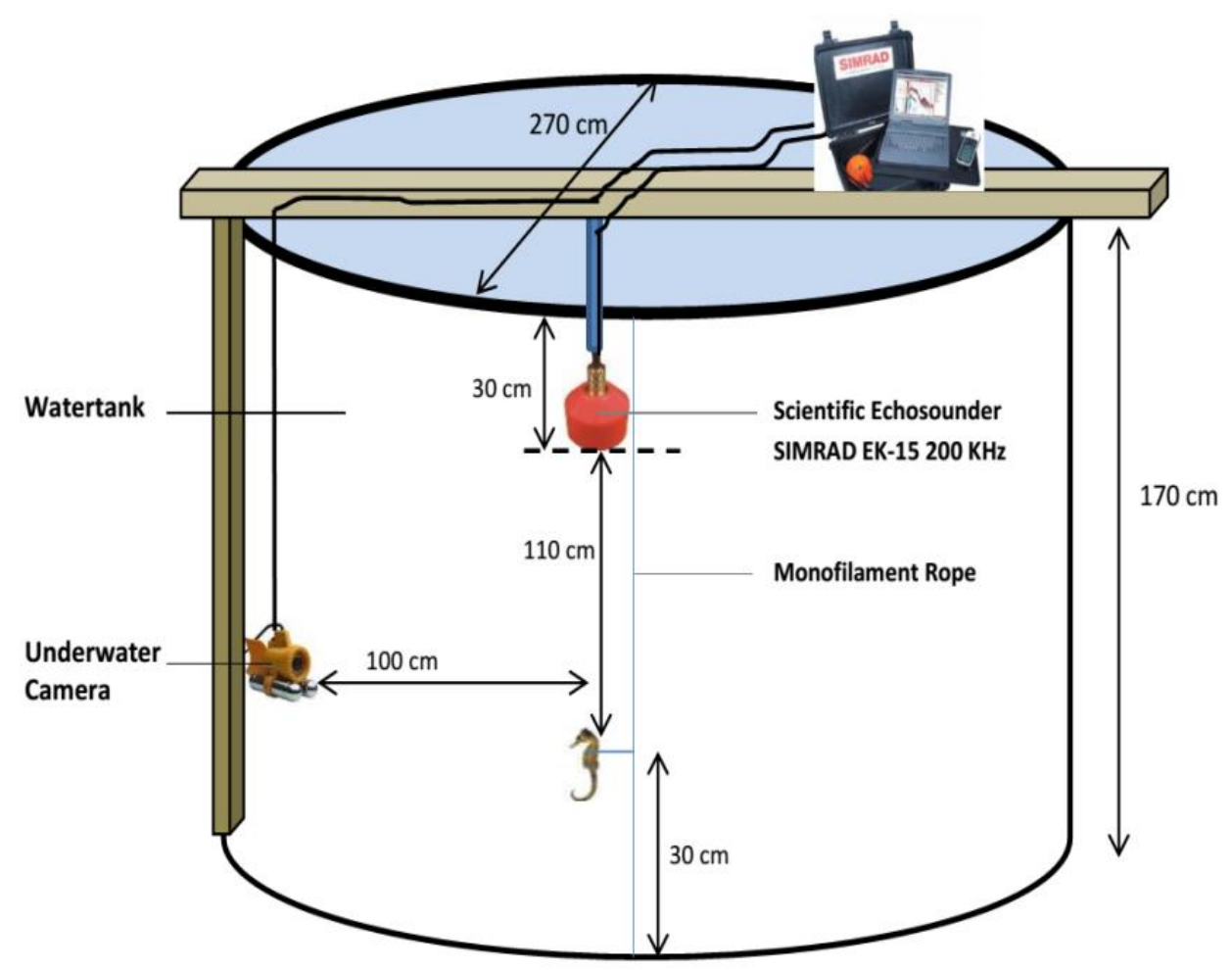

Figure 1. Set-up of water tanks for seahorse experiment (downward looking transducers) using SIMRAD EK-15.

\section{Results and Discussion}

Morphometric measurements of seahorse are done after recording the acoustic data, including length, weight, sex type, given the same repeat on each observation object $\quad(\mathrm{N}=$ $600)$. The result of measuring the average

\section{Fluctuation of Seahorse TS value}

Seahorses' observations in active and passive moving conditions are carried out on the same seahorse, with a time interval of 300 pings for each condition. The calculation area
TS value from the seahorses is ranged in interval -52.31 to $60.91 \mathrm{~dB}( \pm 3 \mathrm{~dB})$. The variability of TS values are influenced by variants of the sample size of various seahorses. The highest TS value is generated on the largest seahorse $(15 \mathrm{~cm})$. Observations results are shown in Table 2.

is divided into 30 segments, each 10 pings per segment (Figure 2). The selection of calculated areas is assisted by the results of underwater video recording.

Table 2. Recapitulation of measurements result of length, weight and mean TS value of seahorses

\begin{tabular}{cccccc}
\hline No & Total Length $(\mathrm{cm})$ & Weigth $(\mathrm{gr})$ & Sex & $\mathrm{N}($ Ping Number) & Mean TS (dB) \\
\hline 1 & 12.5 & 4,56 & Male & 600 & -56.46 \\
2 & 13 & 4,76 & Male & 600 & -60.91 \\
3 & 11 & 3,34 & Male & 600 & -58.61 \\
4 & 15 & 4,77 & Female & 600 & -52.31 \\
\hline
\end{tabular}




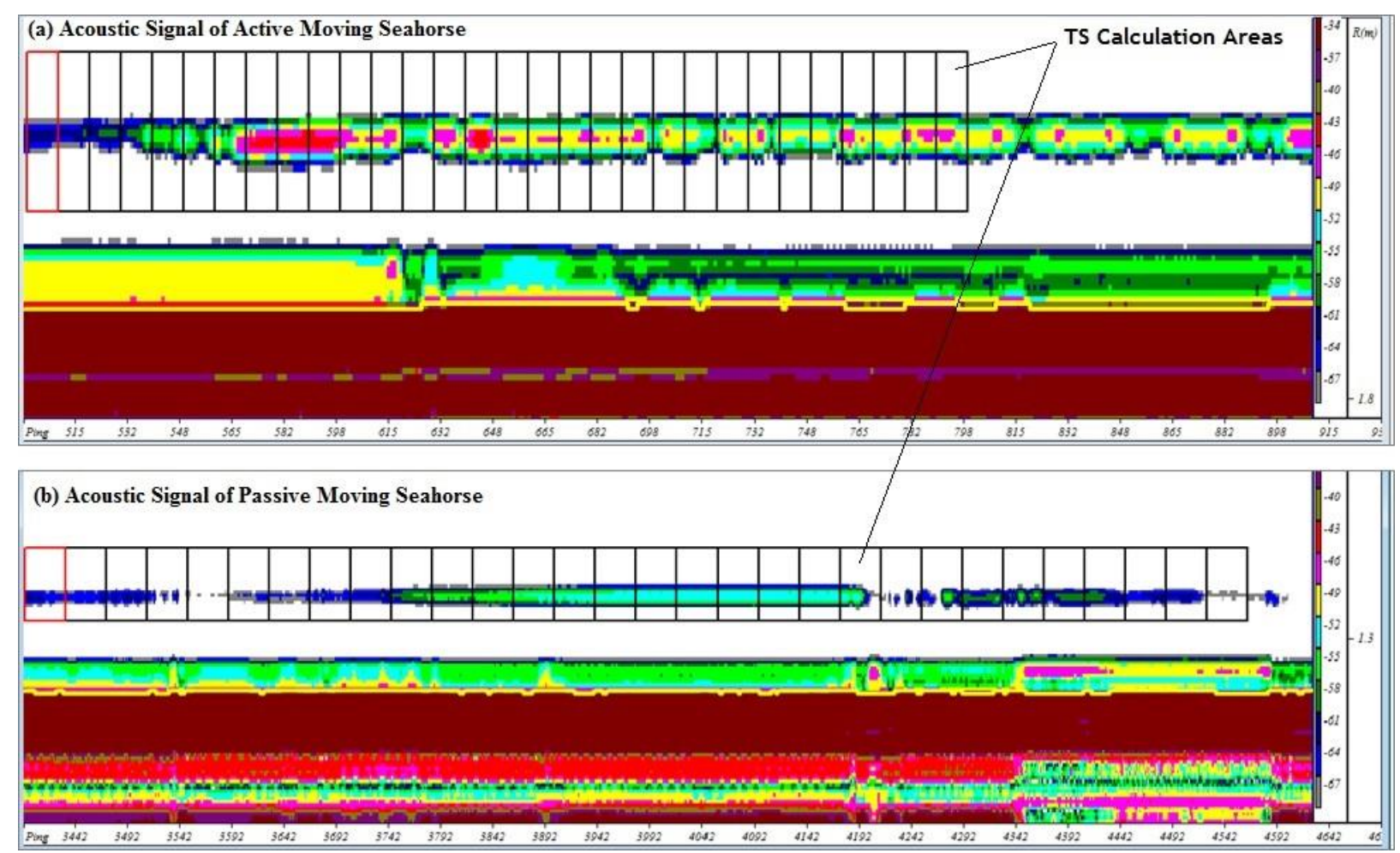

Figure 2. Echograms of seahorse sound signal reflection on moving condition of active (a) and passive (b)

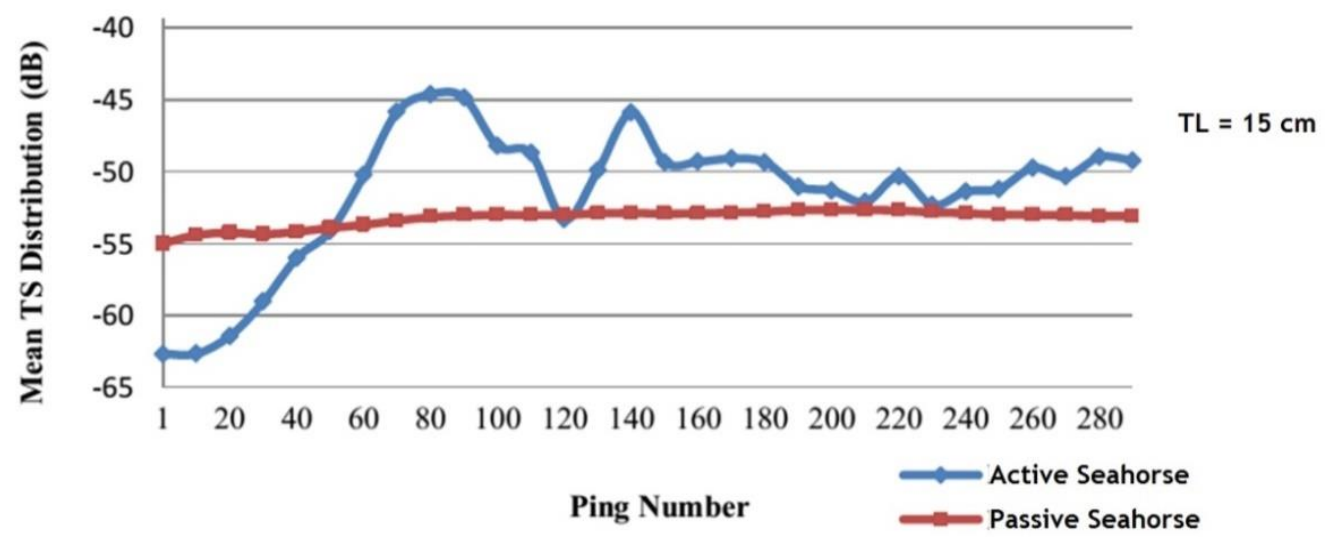

Figure 3. The scatter plot shows the seahorse sound reflection variability

The observation result and measurement show the fluctuation of the seahorse's TS in active moving condition to reach the range 16-18 $\mathrm{dB}$. The fluctuation value is higher than the passive condition about 2-6 dB (Figure 3). This is caused by the change of orientation direction seahorse to the transducer position. It is corresponding with the opinion from Simmonds and MacLennan (2005); Sánchez et. al., (2015) that the TS values of fishes are influenced by the angle of arrival or orientation of the fish toward the transducer. 


\section{Relationship of TS and Size}

Based on the result of linear regression, it shows the correlation of mean TS value with seahorse size in both conditions (active and passive). Although the correlation value is small, but is significant relation. The results of this correlation show that there is a correlation between the average TS value generated against the size (length) of the seahorse observed, especially in passive moving condition (Figure 4). The small correlation value is caused by the small number of treatments (number of seahorse size), but the linear regression result has indicated that the analysis of the determination of the TS value relates to the seahorse size, it is better to use immobile fish technique (seahorse on passive conditions) because it can increase the value of normal data distribution. (a) $\quad(\mathrm{N}=120)$

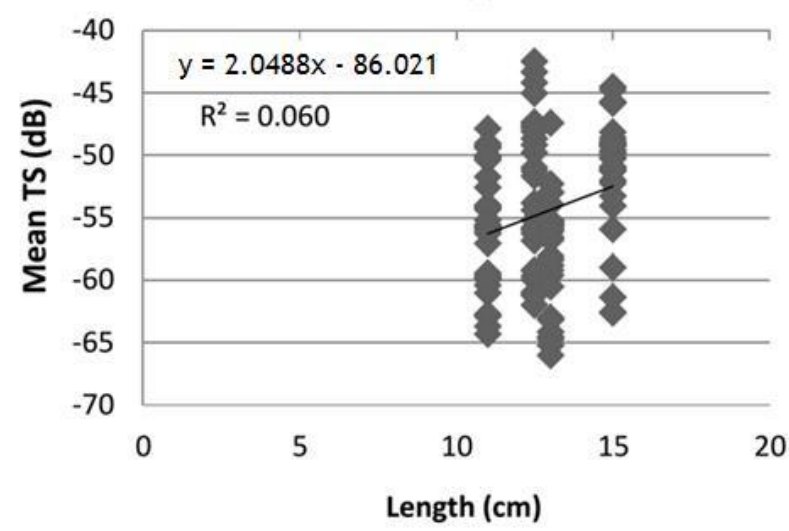

(b)

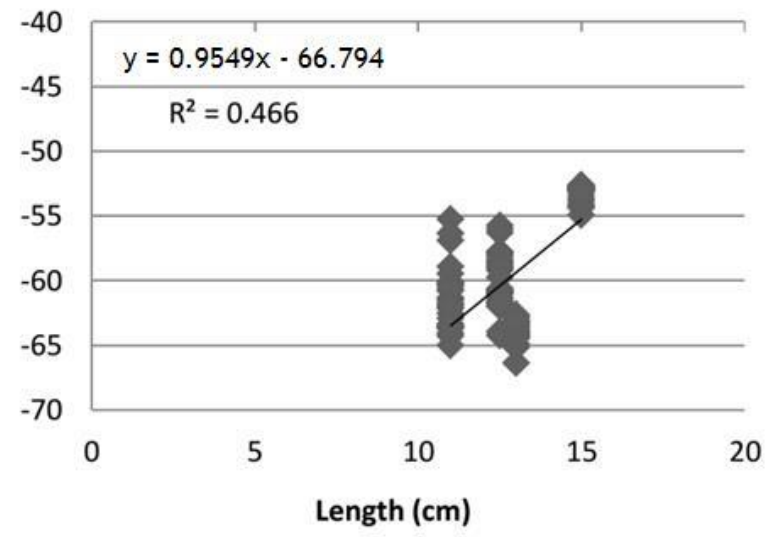

Figure 4. Results of TS relation to the size linear regression on (a) active and passive (b) moving conditions

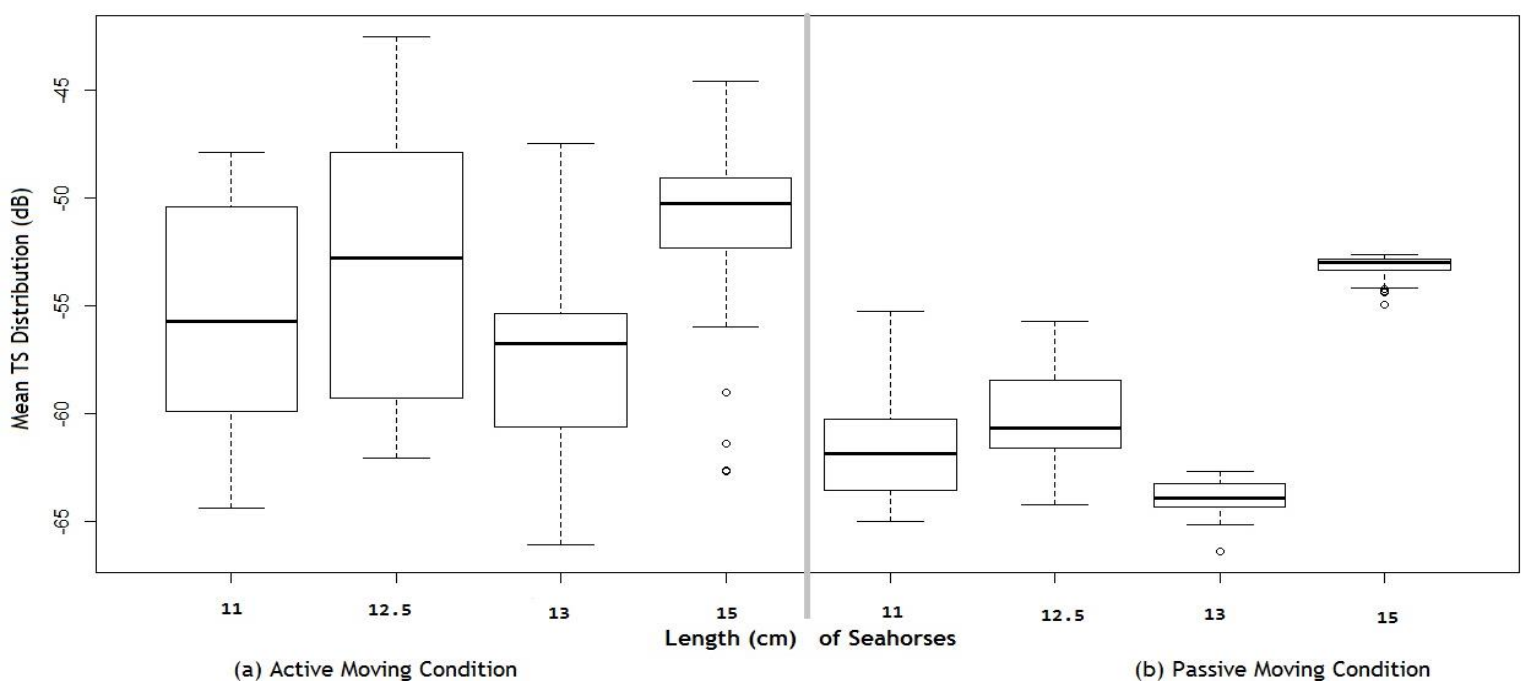

Figure 5. Boxplot of data distribution of the Seahorse TS value difference to size (on active and passive conditions) 
Generally, the average seahorse TS value of the measurement result is $-57.07 \mathrm{~dB} \quad( \pm 3 \mathrm{~dB})$ with a standard deviation of 5.61 . The combined TS distribution (from active and passive moving seahorse conditions) shows a bi- modal (the two peaks) sound intensity (Figure 6). The results of this analysis in detail found the difference in reflection value of seahorse in active moving conditions with values of $-54.49 \mathrm{~dB}( \pm 3 \mathrm{~dB})$. It is greater than the average TS value in passive moving conditions $-59.64 \mathrm{~dB}( \pm 3 \mathrm{~dB})$. However, the standard deviation value of seahorse active moving conditions is larger than the standard deviation value in passive moving conditions, it is reached 5.59 (Table 3). The results of this analysis have reinforced the fact that the seahorse on active moving conditions will increase the fluctuation and variation of the seahorse acoustic reflection value as a result of changes in the orientation direction (Figure 5).

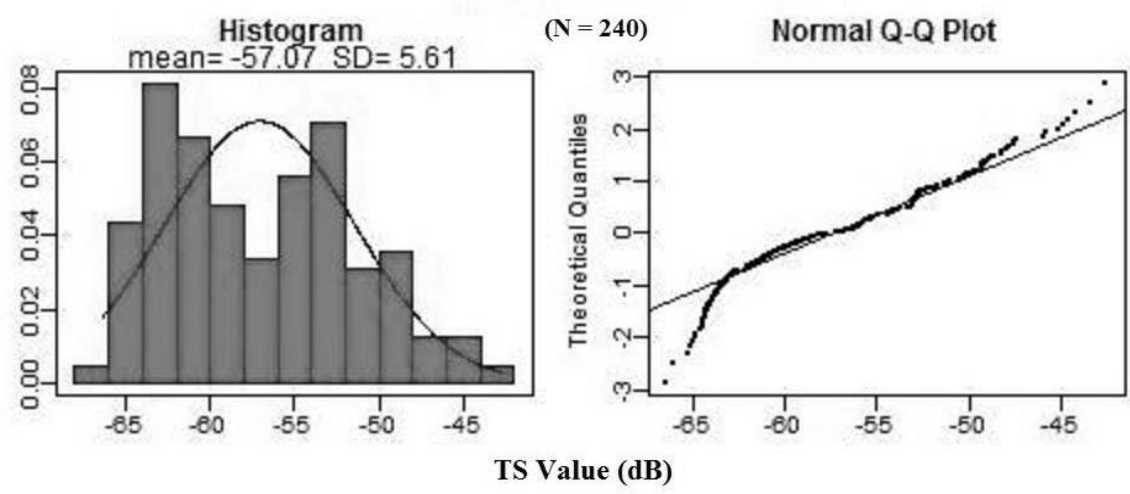

Figure 6. TS Distribution of seahorse (from combination of active and passive moving conditions) based The Probability Density Function (PDF). Left panel: The Gaussian curve shows a bi- modal TS distribution. Right panel: Distribution of TS value variation of seahorse in both conditions. Solid line is the expected normal data distribution.

Table 3. TS average result of multi scatter plot, standard deviation on active and passive moving conditions

\begin{tabular}{lrrrr}
\hline Seahorse Condition & $\mathrm{N}$ & Mean $(\mathrm{dB})$ & $\mathrm{sd}$ & p.overall \\
\hline [ALL] & 240 & -57.07 & 5.61 & \\
Active & 120 & -54.49 & 5.59 & 0 \\
Passive & 120 & -59.64 & 4.31 & \\
\hline
\end{tabular}

The results of anova analysis have shown the difference of TS mean value to seahorse size on active and passive moving conditions ( $p$ value $<0.001$ ) see Table 4. Based on this fact, further test is done to investigating the distribution of data groups from both conditions (active and passive). The result of the Tukey Test shows that the TS value from the active moving condition seahorse is very significantly different than the passive moving condition, see Figure 7.

Table 4. The Anova result of seahorse on active and passive moving conditions

\begin{tabular}{lccccl}
\hline & Df & Sum Sq & Mean Sq & F value & $\operatorname{Pr}(>\mathrm{F})$ \\
Condition & 1 & 1587 & 1587.3 & 63.7 & $6.13 \mathrm{e}-14^{\star \star \star}$ \\
Residuals & 238 & 5931 & 24.9 & & \\
\hline
\end{tabular}

Note: ${ }^{\star \star \star}$ p value $<0.001, \alpha=0.05$ 


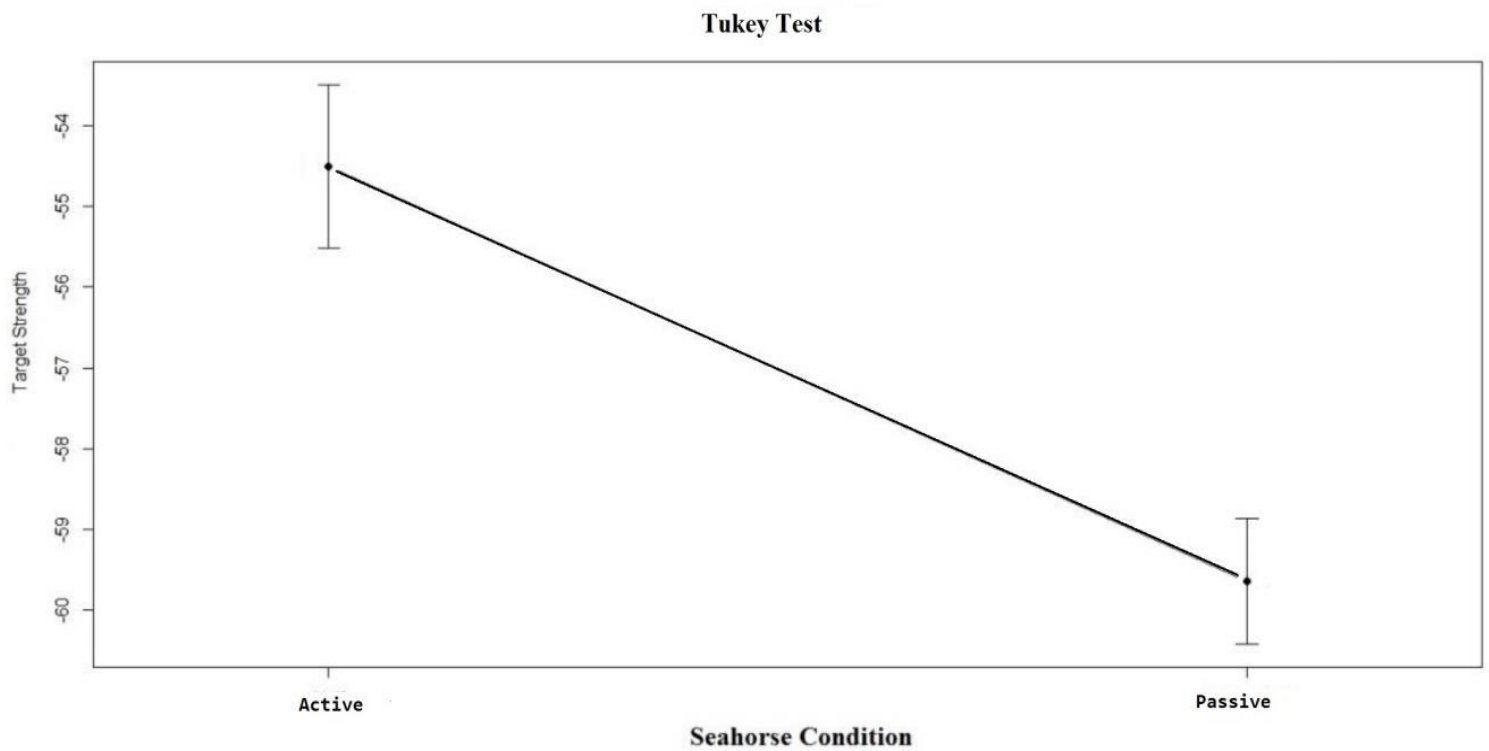

Figure 7. Tukey Test indicate that TS values of seahorse on active and passive moving conditions significantly different statistically

\section{Conclusion}

The conclusions that can be derived from this preliminary study of seahorse sound reflection are as follows:

1. The differences of seahorse acoustic signal reflection fluctuations in active moving conditions reach $16-18 \mathrm{~dB}$. It is higher than in passive moving conditions of 2-6 dB.

2. The mean TS value of a seahorse on active moving conditions is $-54.49 \mathrm{~dB}( \pm 3 \mathrm{~dB})$. It is greater than the mean TS value under passive conditions $-59.64 \mathrm{~dB}( \pm 3 \mathrm{~dB})$.

3. TS values of seahorse on active and passive moving conditions significantly different statistically.

4. The approach of immobile fish (passive condition) of seahorse is better to increase the correlation between TS value and size.

\section{Acknowledgements}

This research is funded by Kemenristek Dikti in 2017 through the Research Grant of Doctoral Dissertation scheme. The authors also appreciates the facilities that have been given by the Laboratory of Aquaculture, Marine Science and Fisheries Faculty of UMRAH in data collection and Laboratory of Signal Processing of Acoustic and Marine Instrumentation Division of IPB Bogor for data processing.

\section{References}

Balk, H., Lindem, T., 2015. Sonar 4 and Sonar 5Pro post-processing systems, Operator manual version 6.0.3, $494 \mathrm{p}$, Lindem Data Acquisition Humleveien 4b. 0870 Oslo, Norway.

Burczynski J J, Johnson R L. 1986. Application of dual-beam acoustic survey techniques to limnetic populations of juvenile sockeye salmon (Oncorhynchus nerka). Canadian Journal of Fisheries and Aquatic Sciences, 43(9): 1776-1788.

Correia, M., Palma J., Koldewey H., Andrade J.P. 2014. The use of a non-invasive tool for capture-recapture studies on a seahorse Hippocampus guttulatus population. Journal of Fish Biology. 84(4). 872-884.

Curtis, J.M.R. 2007. Validation of a method for estimating realized annual fecundity in a multiple spawner, the long-snouted seahorse (Hippocampus guttulatus), using underwater visual census. Fishery Bulletin 105, 327-336.

Dawson, J.J and W.A. Karp. 1990. In situ Measures of target strength variability of individual fish. Rapp. P.V. Reun. Cons. Int. Explor. Mer. 189: 264-273. 
Ehenberg, J.E. 1984. The biosonic dual beam target strength measurement system.. FAO Fish. Circ. 778: 71-78.

Foster, S.J., Vincent A.C.J. 2004. Life history and ecology of seahorse: implications for conservation and management. Journal of Fish Biology 65: 1-61.

Horne J.K. 2003. The influence of ontogeny, physiology and behaviour on the target strength of walleye pollock (Theragra chalcogramma). Ices Journal of marine science. 60: 1063-1074.

IUCN Red List of Threatened Species. Version 2014.3. <www.iucnredlist.org>. Accessed 22 December 2014.

Ona E. 1990. Physiological factors causing natural variations in acoustic target strength of fish. Journal of the Marine Biological Association of the United Kingdom, 70(1): 107-127.

MacLennan, D. N., Fernandes, P. G., and Dalen, J. 2002. A consistent approach to definitions and symbols in fisheries acoustics. - ICES Journal of Marine Science, 59: 365-369.

Manik, H.M. 2009. Quantification of Tuna Fish Target Strength Using Quantitative Echo Sounder. IImu dan Teknologi Kelautan Tropis. Juni 2009. vol. 1 (1) : 33-38

Medwin, H., and Clay. C.S. 1997. Applied Ocean Acoustics: Fundamentals of Acoustical Oceanography. Academic Press, New York. 712 pp.

Project Seahorse, 2014. http://www.projectseahorse.org/, accessed December 2014.

R Core Team. 2016. R: A Language and Environment for Statistical Computing. R Foundation for Statistical Computing, Vienna, Austria. URL https://www.rproject.org/.

Sánchez, V.R., L.E. Encina, A.R. Ruiz, A Monteoliva, R.S., Carmona. 2016. Horizontal target strength of Cyprinus Carpio using $200 \mathrm{kHz}$ and $430 \mathrm{kHz}$ splitbeam systems. Fisheries Research 174 (2016) 136-142.

Simmonds, E.J., Maclennan D.N., 2005. Fisheries Acoustic Theory and Practice. Second Edition. Oxford: Blackwell Science Ltd. Oxford, UK, pp. 437.
Simrad, 2012. Installation manual, Simrad EK15 Multi purpose scientific echosounder, Kongsberg Maritime AS, ISBN 978-828066-147-0.

Yip, M., Lim, A., Chong, V., Lawson, J., \& Foster, S. (2015). Food and feeding habits of the seahorses Hippocampus spinosissimus and Hippocampus trimaculatus (Malaysia). Journal of the Marine Biological Association of the United Kingdom, 95(5), 1033-1040. 